\title{
O MOMENTO DA PESQUISA SOBRE O BUDISMO NO BRASIL: TENDÊNCIAS E QUESTÕES ABERTAS
}

\author{
Frank Usarski
}

Resumo: $\mathrm{O}$ artigo esboça a situação atual da pesquisa sobre o budismo no Brasil e, estimulado pelosoutros textosapresentados nessenúmero de Debates do NER, aborda alguns problemas em função de um futuro debate mais oportuno sobre eles.

Palavras-chave: Censo Nacional - Identidade Budista - Budismo Brasileiro Atitude Teórica.

Abstract: The article sketches the current state of research on buddhism in Brazil and, inspired by the other essays published in this volume, approaches some problems in order to stimulate a future discussion about the respective issues.

Keywords: National Census - Buddhist Identity - Brazilian Buddhism Theoretical Attitude.

\section{CONTEXTUALIZAÇÃO}

Embora o Budismo esteja presente no Brasil desdeo início do século XIX, pelomenos através de uma prática de imigrantesasiáticos(Shoji, 2004a, p. 75), $\mathrm{o}$ interesse acadêmico pelo assunto apenas recentemente ganhou relevo. Vale a pena citar a coletânea $O$ Budismo no Brasil (Usarski, 2002) que foi publicada com o intuito de resumir o "estado de questão" então estabelecido. Até a redação final dos textos reunidos, como a introdução do livro afirma, a pesquisa sobreo tema estava lamentavelmenteatrasada em nossopaís. Diante dessasituação, os capítulos do livro pretenderam estabelecer uma base mais firme em função de uma futura pesquisa mais ampla, diferenciada e profunda.

Um levantamento de projetos ${ }^{1}$ voltados a aspectos históricos ou

Doutor em Ciências da Religião pela Universitat Hannover (Alemanha). Professor no Programa de Pós-Graduação em Ciências da Religião na PUC-SP (usarski@pucsp.br).

${ }^{1}$ Serviu como fonte principal o Banco de Teses da CAPES (http//servicos.capes.gov.br/capesdw/). 
empíricos referentes ao budismo no Brasil ${ }^{2}$ confirma retrospectivamente a adequação tanto da avaliação negativa quanto da esperança com a qual a coletânea foi lançada. Depois de um tímido início na segunda parte dos anos 90 (Rocha, 1997; Matsue, 1998) - sustentado apenas por uma estreita faixa de publicações de outra natureza (Gonçalves, 1971, 1990; Ozaki, 1990) - a prod ução acadêmica vem crescendo desde 2000 e abrange estudos sobre correntes(Veríssimo,2001; Rocha, 2003), comunidades(Marucci, 2000; Pereira, 2001; Silva, 2002), escolas (Gonzaga, 2006) e instituições budistas específicas (Souza, 2006) bem como uma busca para elementos budistas "implícitos" em determinadas expressões e "técnicas" culturais (Fernandes, 2001; Apolloni, 2004; Barreira, 2004).

Este número de Debates do NER é um indicador paradigmático desse movimento em andamento: nele são apresentados textos de autores qualificados, ou por uma dissertação de mestrado (Alves, 2004; Genz, 2005) ou por uma tese de doutorado (Lopes, 2004; Soares, 2004; Shoji, 2004b). As referentes obras foram defendidas em 2004 e 2005, ou seja, em um período decisivo da formação e estruturação do referente campo de pesquisa. É louvável que o saber então demonstrado vem servindo como "matéria-prima" em função de uma produção continua e aperfeiçoada sobre temas afins.

\section{PROBLEMATIZAÇÃO}

Não há espaço para discutir mais detalhadamente as propostas e os resultados de cada um dos artigos. Aproveita-se essa oportunidade para levantar pelo menos três problemas emergentes presentes nos raciocínios dos autores aqui reunidos.

A primeira questão diz respeito ao valor heurístico dos dados do IBGE sobre o peso quantitativo do budismo no Brasil. Como conceber mais realisticamente dentro do referente subcam po religioso, para citar uma formulação do artigo de Daniel Alves, "a relação entre adesão e afirmação

\footnotetext{
2 São omitidos aqui trabalhos de caráter exegético ou filosófico, bem como obras sobre personalidades e problemas relacionados ao budismo clássico fora do Brasil.
} 
de identidade religiosa"? Faz sentido discriminar categoricamente diferentes estilos de religiosidade budista, ou é oportuno subsumir membros definitivos de comunidades manifestas, freqüentadores temporários de templos e participantes esporádicos de retiros sob o rótulo geral "budista"?

A segunda questáo foi implicitamenteabordadana conferência $O$ budismo brasilein durante o FórumSocial Mundial (FSM), em janeiro de 2005, mencionado por Antônio Carlos de Madalena Genz como ponto de partida do seu artigo. Não há dúvida de que, no decorrer de sua história, o budismo tem se adaptado com muito sucesso às condições culturais das suas culturas anfitriãs, inclusive às dos países ocidentais, onde segundo alguns autores já se desenvolveu uma espécie de um "quarto veículo", com determinadas especificidades distintas dos três veículos clássicos, (Teravada predominante na Ásia do Sul, Mahayana enraizado no Extremo Oriente e Vajrayana, como a religião majori tária dos tibetanos e outros povos da região do Himalaia). É oportuno aproximar-se do budismo manifesto no Brasil em termos análogos?

A terceira questão emerge especificamente de textos, ou pelo menos de alguns trechos que refletem uma paixão explícita pelo objeto de "estudo". Não se questiona a legitimidade de um entusiasmo religioso em si, mas valerão a pena fazer algumas observações sobre a relação entre o autor "crente" e o autor membro de uma comunidade científica comprometida com uma abordagem ideologicamente "controlada".

\section{REFLEXÃO}

Problemas da QUANTIFICAÇÃo Do BUdismo No BRASIL

Conforme os dados apontados no último censo em 2000, os budistas no Brasil somaram cercade 214.873 participantes. Houve, em comparação com o censo de 1991, um declínio absoluto de 21.532 adeptos. Vale lembrar que tais números não refletem qualquer tipode distorção por errosmetodológicos.Pelo contrário:notávelé a regularidade coma quala estagnaçãoou mesmoo declínio numérico do campo budista é constatado por meios estatísticos. As respectivas informaçôesnão se restringemaos últimos censos nacionais, mas incluem também dados posteriores. Entre os últimos, encontram-se os resultados de uma 
pesquisa feita em 19 capitais brasileiras, apresentados pelo IBGE em 9 de maio de 2006 à Assembléia Geral dos Bispos do Brasil. Em relaçáo ao budismo, afirmou-se que, devido à presença de 90.000 mil budistas em São Paulo, isto é, $0,6 \%$ da população da metrópole, aquela cidade "é a única capital brasileira com presença expressiva desse grupo religioso." Isso significa que em outras grandes cidades do país o budismo é estatisticamente muito fraco ou, até mesmo, quase inexistente. Uma pesquisa telefônica nacional do IBOPE Opiniāo realizada nos dias 17 e 18 de abril de 2006 sobrea simpatia dos brasileirospelo budismo apontou para a mesma direçao: $20 \%$ dos entrevistados informarem não saber nada sobre essa religião, $63 \%$ disseram a conhecer apenas "de ouvir falar" e 13\% responderam conhecê-la "mais ou menos", enquanto uma minoria de 3\% disse "conhecer bem" a religião. ${ }^{4}$ A partir da hipótese de que a probabilidade de que alguém se converta a uma religião cresce na medida em que ele a conhece, pode-se deduzir dos dados acima que o terreno em que o budismo poderia se expandir é até hoje consideravelmente pequeno.

Todavia, não é preciso ser um budista convicto para questionar o grau da pertinência dessas e de outras estatísticas. Qualquer cientista social sabe das limitações de dados desse tipo, especialmente quando eles se referem a um país cujos habitantes mostram em grande escala uma "múltipla afiliação religiosa" devido a uma alma coletiva na qual o "ecletismo é profundamente enraizado" (Carpenter, 1995, p. 48). Consciente de problemas inerentes a uma abordagem puramente quantitativa, como interpretar mais adequadamente o declínio de budistas de carteirinha no Brasil nas últimas décadas? Não se pretende dar uma resposta final a essa questão. A intenção das observações é apenas estimular o futuro debate sobre os respectivos problemas.

Propóe-se como ponto de partida o critério clássico estabelecido pela própria tradição budista que permite uma distinção inequívoca entre membros e não-membros da própria religião. Trata-se das chamadas três jóias, isto é, a seguinte fórmula tripla publicamente confirmada pelo adepto: "Tomo refúgio no Buda. Tomo refúgio no Dharma. Tomo refúgio na Sangha”.

3 “Católicos em São Paulo passaram de 78,7\% para 68,4\%”, Estado de São Paulo, 10 maio de 2006.

${ }^{4}$ Conforme http://www.ibope.com.br/opiniao_publica/downloads/opp071_budismo_ abr06.pdf 
Dois aspectos inter-relacionados desse "testemunho de fé" chamam a atenção. O primeiro está no fato de que, segundo a fórmula tripla, um adepto não se torna um budista por reconhecer apenas a autoridade do Buda e a consistência soteriológica da sua doutrina (dharma). $\mathrm{O}$ ato de adesão ao budismo é apenas concluído quando também a comunidade budista (sangha) for explicitamente aceita como elemento constitutivo da nova identidade religiosa. Tradicionalmente, a sangha tem uma estrutura quádrupla, ou seja, o termo diz respeito à ordem monástica composta por monges e monjas quanto a leigos e leigas budistas. Portanto, do ponto de vista tradicional, a consciência de fazer parte de uma entidade social maior que abrange homens e mulheres com a mesma orientação religiosa é um elemento constitutivo da identidade budista individual.

O segundo aspecto tem a ver com os significados da palavra "refúgio". Conforme o Dicionário Michaelis e o Dicionário Aurélio, respectivamente, um refúgio é lugar seguro, um local para onde alguém foge a fim de estar em segurança. Esses conceitos repercutem na fórmula tripla no sentido de que a adesão ao budismo é manifestação de uma atitude firme e sólida, que faz com que a respectiva oferta religiosa seja aceita como válida. Em outras palavras: a repetição da fórmula tripla como manifestação de uma atitude religiosa é feita a partir de uma decisão consciente a favor do budismo. De tipo ideal, trata-se de uma opção exclusivista que desvaloriza qualquer outra oferta ideológica ou como menos relevante ou, até mesmo, como insignificante. Essa confiança de estar "no caminho certo", portanto, distingue-se fenomenologicamente de uma "espiritualidade em construção", de uma "identidade religiosa flexível-flutuan te" e de "créd ulos difusos", ou seja, de características não apenas associadas a "crenças e práticas místicoesotéricas" no ambiente da chamada Nova Era (Siqueira, 2003, p. 25).

Duvida-se da funcionalidade de uma definição mais branda da noção "budista”, mas reconhece-se que uma religião de origem oriental transplantada para países ocidentais exige um tratamento conceitual diferenciado. Por conseguinte, sugerese uma dist inção entre "budistas" e "impacto do budismo", seja no sentido de uma adoção individual seletiva de algumas das suas doutrinas e/ou práticas, seja no sentido de uma influência mais geral e indireta, por exemplo, sobre determinadas artes marciais ou expressóes estéticas como a poesia, arranjos de flores, etc. 
Quanto à adoção individual dessa religião, deve-se pensar em um continuum marcado por dois extremos. Um é representado por budistas propriamente ditos, na melhor das hipóteses de acordo com a formula tripla, ou pelo menos no sentido de "portadores" de uma identidade religiosa predominantemente budista que faz com que as referentes pessoas se autoidentifiquem, diante de um entrevistador do IBGE, como aderentes definitivos do budismo. O outro extremo do continuum dos diferentes graus de adesão ao bu dismo consta em uma apropriação "espontânea" de elementos budistas que se "emanciparam" do seu con texto original e começaram a circular livremente. Conforme Gabriela Bastos Soares, nesses casos

o budismo é visto como componente do cosmos sagrado da atualidade. Os principais aspectos que contribuem para essa afirmação são: o exercício a nível individual, privado, reconhecido como uma psicologia budista; o pragmatismo desse tipo de religião, fundamentada em regras úteis para o mundo; e a relação com outras pessoas e com o universo, que enaltece uma cosmovisäo holística. (Soares, 2004, p. 144).

Questiona-se a pertinência de conceber pessoas caracterizadas dessa maneira como budistas, reconhece-se apenas que alguns aspectos do budismo são constitutivos para sua religiosidade fenomenologicamente mais ampla. Entre os dois extremos, isto é, entre a identificação explícita como budista e internalização difusa de elementos seletivos inerentes ao budismo, encontra-se um vasto espectro de graus de aproximação dessa religião representado por depoimentos do seguinte tipo:

"Seique os ensinamentos funcionam", porém, "até hoje não sei se sou budista." (Silva, 2002, p. 156, p. 132). "Eu ainda sou apenas um simpatizante do budismo [...]. Nosso país é um país tradicionalmente católico e a maioria da população, assim como eu, foi criada e educada nos moldes da igreja católica, que traz a figura de Deus personificado, à nossa imagem e semelhança. Talvez seja esse o ponto crucial, o conceito mais difícil de ser mudado ou entendido, visto que no budismo não existe a figura do Deus personificado."

${ }^{5}$ Citação de um e-mail enviado por Luiz Fernando em 23 de setembro de 2004 para a lista buddhismo@topica.com. 
Espere-se que as ponderações acima sejam retomadas em posteriores publicações e contribuam para a solução de diversas outras perguntas abertas sobre esse tema.

QuestōES COM RELAÇÃO A ESPECULAÇÕES SOBRE UM "BUdISMO BRASILEIRO”

Especulaçōes sobre a possível existência de um "budismo brasileiro" apontam para a questão mais geral: sob quais condições uma religião transplantada é capaz de se adaptar às peculiaridades da sua nova cultura anfitriã? Vale a pena lembrar de respectivas reflexóes do sociólogo norte-americano Rodney Stark (1996) capazes de aprofundar a discussão sobre o status atual e o potencial futuro do budismo no Brasil.

Stark definiu dez pressupostos segundo os quais uma religião transplantada ou recém-fundada tem boas chances de se assimilar ao seu novo ambiente. Uma das exigências-chave que deve ser levada em conta, especificamente quando se trata de uma religião transplantada, consta na diminuição de um "abismo ideológico" entre as doutrinas religiosas originalmente alheias e a herança cultural predominante na sociedade anfitriá. No caso do budismo, a tarefa da "mediação" en tre a própria tradição e o novo público pressupõe uma adaptação lingüística do seu "material", não apenas dos seus "livros sagrados" e manuais originalmente escri tos em páli, sânscrito, chinês, japonês ou tibetano, mas também no sentido de uma tradução e comentários dos seus termos "técnicos" conforme as regras e peculiaridades de comunicação, inclusive as denotações e conotações promovidas pela língua materna do novo público (Notz, 1984). Sabe-se, por exemplo, que o budismo não teria feito tanto sucesso entre europeus e norte-americanos se não tivesse havido uma interpretação de seus elementos-chave no espírito da psicologia ocidental (Suzuki, 1989).

O sucesso ou fracasso desse processo de aproximação simbólica depende da faculdade de seus protagonistas de criar pontes entre a oferta e uma nova clientela sem vulgarizar a primeira. Para usar uma expressão de Rodney Stark, os transmissores são confrontados com a tarefa de manter uma "média tensão" entre a religião trazida e a cosmovisão predominante da cultura anfitriā. Caso isso não ocorra, deve-se ao fato de que a nova mensagem é 
apresentada em termos inacessíveis ou que o público potencial não se sente atraído por uma retórica que parece apenas confirmar convicçôes religiosas já estabelecidas na sociedade anfitriā.

Um outro elemento fundamental enfatizado por Stark é a qualidade organizacional da religião em questão. Isso significa, entre outros aspectos, que a nova religião deve ter o caráter de uma rede social aberta para garantir um intercâmbio permanente entre a própria comunidade e o ambiente social e o "input" de novos ad eptos.

Os limites formais do presente artigo não permitem uma discussão detal hada sobre a questão se, ou até que grau, o budismo no Brasil corresponde aos critérios sugeridos por Rodney Stark. Há apenas espaço para alguns comentários e a formulação de algumas perguntas abertas a fim de estimular o debate em circunstâncias mais oportunas.

Em primeiro lugar, deve-se lembrar que, enquanto em países como Alemanha, Inglaterra e França traduçóes de textos clássicos budistas de alto nível têm servido como importantes referências para convertidos ao budismo, o Brasil sofre uma falta de entidades universitárias dedicadas a filologias extra-européias e, portanto, de especialistas que poderiam ser consultados no processo de adaptação do material em que as diferentes linhas budistas se baseiam. Essa situação precária afeta as correntes tradicionais predominantemente étnicas mais do que grupos budistas que antes de chegar ao Brasil já haviam passado por experiências em solo ocidental, como a Soka Gakkai ou a New KadampaTradition, que assumiramum caráter globalizado também no que respeita ao material usado nas suas filiais brasileiras.

Independentemente disso, qualquer brasileiro que se apresente ao seu público como um líder religioso - seja como "monge" em nome do budismo zen, como "lama" em nome do budismo tibetano, como "reverendo" em nome da escola da Terra Pura ou como "Dham macariya" em nome do budismo teravada - não se qualifica automaticamente pelo "título" adquirido ou assumido, mas sim pela duração e profundidade da sua formação religiosa, pela reputação da instituição que a forneceu e por sua competência didática em transmitiras referentes doutrinas e métodos para seu público.Além disso, o possível desenvolvimento do budismo no Brasil na direção de um budismo brasileiro dependerá consideravelmente da sua capacidade de vencer as ten- 
sões entre determinadas linhas e de transformar um órgão como o recémfundado Colegiado Buddhista Brasileiro, de uma assembléia simbólica composta por "personalidades budistas" escolhidas em um instrumen to político prático em nome de todos os praticantes dessa religião.

\section{ANOTAÇÕES METODOLÓGICAS}

Como afirma Alfred Schütz, fundador da Sociologia Fenomenológica, a esfera da ciência é predominada por uma consciência de seus representantes que difere qualitativamente do estilo cognitivo típico do cotidiano. Schütz tematizou essas duas maneiras de tratar o mundo em termos da dicotomia atitude teórica versus atitude natural, ou seja, de dois estilos cognitivosdos quais o primeiro pode ser caracterizado da seguinte maneira: "A atitude natural é a atitude da consciênciado sensocomum [...]. Não requer maiorverificação, que se estenda além de sua simples presença. Está simplesmente aí, como faticidade evidente por si mesma e compulsória.” (Berger, 2000, p. 40). Deve-se destacar que a atitude natunal não se restringe a constituintes meramente cognitivos. Trata-se de uma posição na vida cotidiana que depende da personalidade de homens e mulheres em todosos seus aspectos, inclusivenos de crenças e valores religiosos. Como todos os outros indivíduos, um cientista da religião, em sua vida privada, faz parte da rede de plausibilidades descrita acima.

Em oposição à atitude natural, o termo atitude teórica designa o ideal de uma consciência disciplinada com a qual um cientista exerce sua tarefa de acordo com as regras metodológicas da sua disciplina. Nesse sentido, a atitude teórica é caracterizada pela disposição do indivíduo para "não aceitar nenhuma condição e nenhum fenômeno como simplesmente existentes, ausentes da necessidade de explicação" (Schütz, 1974, p. 15). Com isso, Schütz exigiu que um cientista institucionalizasse, como uma instância interna, a chamada dúvida metodológica. Está dúvida se refere a qualquer segmento da realidade, inclusiveaqueles aspectos que parecem não-problemáticos do ponto de vista de uma atitude natural na vida particular do cientista.

Comparado com esse ideal, esse número de Debates do NER provoca dúvidas metodológicas, em especial o artigo de Ana Cristina Lopes Nina. 
Pergunta-se diante do título, da linguagem afirmativa e da bibliografia seletiva do artigo: o texto foi proposto com a pretensão de oferecer uma reflexão científica ou como uma espécie de narrativa sobre acontecimentos extraordinários na presença de um líder carismáticocujo elevado status soteriológico impede uma abordagem analítica propriamente dita?

Reafirma-se a necessidade de que um autor se afaste, ao exercer sua função acadêmica, da atitude de "cren te" e assuma a posição de um "observador". Ninguém colocaria essa exigência em questão caso se tratasse de u m artigo afirmativo sobre as bênçãos da teologia de prosperidade em uma igreja pentecostal local. Uma vez que a atitude teórica foi formulada como um princípio epistemológico universal, as mesmas regras têm que ser aplicadas a qualquer objeto de estudo, inclusive o budismo.

\section{OBSERVAÇÕES FINAIS}

As anotações acima foram feitas na esperança de um futuro diálogo mais frutífero entre os pesquisadores brasileiros engajados na pesquisa sobre o budismo no país. Os autores ora reunidos demonstram que a referida "rede" está em ação. Chama-se atenção ao fato de que além de publicações como esta, existe uma estrutura "institucional" preparada para tal discussão. Nesse sentido, espera-se que entidades como o grupo CERAL (Centro de Estudos de Religiōes Alternativas de Origem Oriental, localizado na PUC de São Paulo $)^{6}$ e o grupo de pesquisa sobre Religiōes Orientais da Associação Brasileira da História das Religiōes (ABHR) ${ }^{7}$ sejam possíveis outros fóruns para o intercâmbio sobre uma série de questóes abertas sobre o espectro temático abordado pelo presente número de Debates do NER.

\footnotetext{
${ }^{6}$ Conforme http://www.pucsp.br/pos/cre/ceral/.

${ }^{7}$ Conforme http://members.tripod.com/bmgil/gp.html.
} 


\section{REFERÊNCIAS}

ALVES, Daniel. "Seres de sonho: percursos religiosos e práticas espirituais num centro budista ao Sul do Brasil”. Dissertação (Mestrado em Antrop ologia Social) - PPGAS/UFRGS, Porto Alegre, 2005.

APOLLONI, Rodrigo Wolff. "Shaolinà Brasileira”: Estudo sobre a Presença e a Transformação de Elementos Religiosos orientais no Kung-Fu Praticado no Brasil. Disser tação (Mestrado em Ciências da Religião) - Programa de Estudos Pós-Graduados em Ciências da Religião/PUC-SP, São Paulo, 2004.

BARREIRA, Cristiano Roque Antunes. Arqueologia da Intenção do Caminho doKarate. AnálisePsicológicae Fenomenológica.Tese(Doutorado emPsicologia) - Programa de Pós-Graduação em Psicologia-USP, Ribeirão Preto, 2004.

BERGER, Peter L.; Luckmann, Thomas. A Construção Social da Realidade. Petrópolis: Vozes, 2000.

CARPENTER, Robert T.; WADE, Clark Roof. The Transplantation of Seicho-no-ie from Japan to Brazil: Moving Beyond the Ethnic Enclave, Journal of Contemporary Religion. Vol. 10, n. 1, p. 41-54, 1995.

FERNANDES, Carlos Magno Pereira: Entre o Mero e o Esmero: a Margem do Riso na Poesia de Paul Leminski. Dissertação (Mestrado em Estudos da Linguagem) - PPGEL/UFRN, Natal, 2001.

GENZ, Antônio Carlos de. A música silenciosa do Darma: um estudo Antropológico das práticas e representaçôesde uma comunidade zen budista em Porto Alegre. Dissertação (Mestrado em AntropologiaSocial) - PPGAS/ UFRGS, Porto Alegre, 2005.

GONÇALVES, Ricardo Mário. A religião no Japão na época da emigração para o Brasil e suas repercussōes em nosso país, In: O Japonês em São Paulo e no Brasil. Relatório do Simpósio realizado em junho de 1968 ao ensejo do $60^{\circ}$ Aniversário da Imigração Japonesa para o Brasil. São Paulo: Centro de Estudos Nipo-Brasileiros, 1971. p. 58-73. 
. O Budismo Japonês no Brasil: Reflexôes de um Observador Participante. Cadernos do ISER: Sinais dos Tempos - Diversidade Religiosa no Brasil. Rio de Janeiro, n.23, p. 167-180, 1990.

GONZAGA, Elisabeth. Buda de Casa faz Milagre? Estudo sobre o Conflito entreTradição e Modernidade em Gruposda Escola Jôdo Shinshuem Suzano (SP). Dissertação (Mestrado em Ciên cias da Religião) - Programa de Estudos Pós-Graduados em Ciências da Religião/PUC-SP, São Paulo, 2006.

MARUCCI, Cynthia Moreira. Budismo tibetano no Brasili a Experiênáa do Jardim do Dharma. Dissertação (Mestrado em Ciências Sociais) - Programa de Estudos Pós-Graduados em Ciências Sociais/PUC-SP, São Paulo, 2000.

MATSUE, ReginaYohhi.OParaísodeAmida TrêsEscolasdo Budismo emBrasilia Dissertação (Mestrado em Antropologia Social) - PPGAS/UnB, Brasília, 1998.

LOPES, Ana Cristina. Ventos da impermanência: um estudo sobre a resignificaçãodo BudismoTibetano no contexto da diáspora.Tese(Doutorado em An tropologia Social) - PPGAS/USP, São Paulo, 2004.

NOTZ, Klaus-Josef. Der Buddhismus in Deutschland in seinen Selbstda rstellungen. Eine religion swissen schaftl iche Untersu-ch ung zur religiösen Akkulturationsproblematik. Frankfurt/M.: Peter Lang, 1984.

OZAKI, André Mazao. As Religiōes Japonesas no Brasil. São Paulo: Edições Loyola, 1990.

PEREIRA, RonanAlves.O BudismoLeigoda SôkaGakkaino Brasil: daRevolução Humana à Utopia Mundial. Tese (Doutorado em Ciências Sociais) - Programa de Doutorado em Ciênđas Sociais/UNICAMP, Campinas-SP, 2001.

ROCHA,Antonio Carlos Pereira Borba.Zen-Budismoe Literatura: A Poética de Gilberto Gil. Dissertação (Mestrado em Letras) - Programa de PósGraduação em Ciências da Literatura/UFRJ, Rio de Janeiro, 1997.

ROCHA, Cristina Moreira da. Zen in Brazil: The Quest for Cosmopolitan Modernity. PhD (Thesis)-Centre for Cultural Research/University of Western Sidney, Sidney, 2003. 
SOARES, Gabriela Bastos. O biopoder na contemporaneidade: o espírito do corpo e a alternativabudista. Tese (Doutorado em Saúde Coletiva) - PPGSCIMS/UERJ, Rio de Janeiro, 2004.

SCHÜTZ, Alfred. Der sinnhafte Aufbau der so-zialen Welt, Eine Ein-leitung in die verstehende Soziologie. Frankfurt/M.: Suhrkamp, 1974.

SHOJI, Rafael. Reinterpretação do Budismo Chinês e Coreano no Brasil. REVER - Revista de Estudos da Religião. São Paulo, n. 3, p.74-87, $2004 a$.

. The Nativizationof East Asian Buddhism in Brazil. Tese (Doutorado em Ciências da Religião) - Universitat Han nover, Hanôver, 2004b.

SILVA, Vera de Andrade de. Conversão ao Budismo Tibetano. Trajetórias em Três Grupos de São Paulo. Dissertação (Mestrado em Ciências da Religião) - Programa de Estudos Pós-Graduados em Ciênciasda Religião/PUC-SP, São Paulo,2002.

SIQUEIRA, Deis. A Labiríntica Busca Religiosa na Atualidade: Crenças e Práticas Místico-Esotéricas na Capital do Brasil, In: Siqueira, Deis; Ricardo Barbosade Lima (Org.). Sociologia das Adesões: NovasReligiosidades e a Busca Mística na Capital do Brasil. Rio de Janeiro: Garamond, 2003, p.25-64.

SOUZA, Denise Lopes de. Diploma de Monge - Um estudo sobre a Universidade Livre Budista da Fo Guang Shan, Dissertação (Mestrado em Ciên cias da Religião) - Programa de Estudos Pós-Graduados em Ciências da Religião/PUC-SP, São Paulo, 2006.

STARK, Rodney. WhyReligious Movements Succeedor Fail: a RevisedGeneral Mode. Joumal of Contemporary Religion. Vol. 11, n. 2, p.133-146, May 1996.

SUZUKI,T.;Fromm, Erich, RichardDe Martino.Zen-Budismo e Psicanálise. São Paulo: Cultrix, 1989.

USARSKI,Frank. O Budismono Brasil- um resumosistemático. In: (Org.). O Budismo no Brasil. São Paulo: Lorosae, 2002, p. 9-33.

VERÍSSIMO, Jane Costa dos Reis. A Memória e a Impermanência: o Budismo Tibetano no Brasil (1980-2000). Dissertação (Mestrado em Memória Social) - PPGMS/UNIRIO, Rio de Janeiro, 2001. 